\title{
AS DIMENSÕES TEMPO E ESPAÇO EM PRÁTICAS DE EDUCAÇÃO INTEGRAL: IMPLICAÇÕES CURRICULARES A PARTIR DO DIÁLOGO ENTRE PAULO FREIRE E DARCY RIBEIRO
}

\author{
LAS DIMENSIONES TIEMPO Y ESPACIO EN PRÁCTICAS DE EDUCACIÓN \\ INTEGRAL: IMPLICACIONES CURRICULARES A PARTIR DEL DIÁLOGO ENTRE \\ PAULO FREIRE Y DARCY RIBEIRO
}
THE DIMENSIONS OF TIME AND SPACE IN COMPREHENSIVE EDUCATION PRACTICES: CURRICULAR IMPLICATIONS BASED ON THE DIALOGUE BETWEEN PAULO FREIRE AND DARCY RIBEIRO

\author{
Dinora Tereza ZUCCHETTI ${ }^{1}$ \\ José Leonardo Rolim de Lima SEVERO
}

RESUMO: O texto, na forma de ensaio, tem como ancoragem transcrições de pronunciamentos de Paulo Freire e Darcy Ribeiro para refletir sobre as dimensões tempo e espaço em práticas de educação integral, nos dias de hoje. Passados quase trinta anos nos vemos mediante situações que, em muito, lembram a realidade de outrora. Contudo, mais recentemente, a exemplo do Programa Mais Educação, viu-se ocorrer ensaios no campo das políticas sociais para enfrentar o dilema da ampliação do tempo e do alargamento dos espaços na busca por criar alternativas para educar crianças e adolescentes pior situados socialmente. Apontamos que a gestão do tempo e dos espaços formativos através do currículo é uma questão chave na construção de propostas institucionais que conduzam a esse alargamento enquanto estratégia de garantia do direito uma educação crítica, integradora e problematizadora.

PALAVRAS-CHAVE: Educação integral. Currículo. Paulo Freire. Darcy Ribeiro.

RESUMEN: El texto, en forma de ensayo, tiene como base transcripciones de declaraciones de Paulo Freire y Darcy Ribeiro para reflexionar sobre las dimensiones tiempo y espacio en prácticas de educación integral, en los días de hoy. Pasados casi treinta años nos vemos ante situaciones que, en mucho, recuerdan la realidad de otrora. Sin embargo, más recientemente, por ejemplo, en el Programa Mais Educação, ocurrieron ensayos en el campo de las políticas sociales para enfrentar el dilema de la ampliación del tiempo y el ensanchamiento de los espacios en la búsqueda de crear alternativas para educar a los niños y adolescentes peor situados socialmente. Observamos que la gestión del tiempo y de los espacios formativos por

\footnotetext{
${ }^{1}$ Universidade Feevale (FEEVALE), Novo Hamburgo - RS - Brasil. Professora do programa de pós-graduação em Diversidade Cultural e Inclusão Social. Líder do Grupo de pesquisa de Estudos e Pesquisas em Educação Não Escolar. Pesquisadora do Grupo de Estudos e Pesquisas em Pedagogia, Trabalho Educativo e Sociedade (GEPPTES). Produtividade em Pesquisa (CNPq). Orcid: https://orcid.org/0000-0002-7122-1025 E-mail: dinora@feevale.br

${ }^{2}$ Universidade Federal da Paraíba (UFPB), João Pessoa - PB - Brasil. Professor Permanente do programa de pósgraduação em Educação. Líder do grupo de estudos e pesquisas em Pedagogia, Trabalho Educativo e Sociedade (GEPPTES). Pesquisador do Grupo de Estudos e Pesquisas em Educação Não Escolar. ORCID: https://orcid.org/0000-0001-5071-128X).E-mail: leonardosevero@ce.ufpb.br
}

RIAEE - Revista Ibero-Americana de Estudos em Educação, Araraquara, v. 15, n. 2, p. 560-577, abr./jun. 2020. e-ISSN: 1982-5587. 
medio del currículo es una cuestión clave en la construcción de propuestas institucionales que conduzcan a esa ampliación como estrategia de garantía del derecho a una educación crítica, integradora y problematizadora.

PALABRAS CLAVE: Educación integral. Currículo. Paulo Freire. Darcy Ribeiro.

ABSTRACT: The text, in the form of an essay, is anchored by transcriptions of pronouncements by Paulo Freire and Darcy Ribeiro to reflect on the dimensions of time and space in curent practices of integral education. Almost thirty years later, we see ourselves through situations that remind us of the reality of the past. However, more recently, as in the case of the program "Mais Educação", there have been assays in the field of social policies to address the dilemma of expanding time and widening the scope of the search for alternatives to educate children and adolescents who are worse off socially. We point out that the management of time and of the formative spaces through the curriculum is a key issue in the construction of institutional proposals that lead to this enlargement as a strategy to guarantee the right to a critical, integrative and problematizing education.

KEYWORDS: Integral education. Curriculum. Paulo Freire. Darcy Ribeiro.

\section{Introdução}

Com o propósito de reafirmar a importância de estudos sobre a educação em tempo integral, escolas em tempo integral e educação integrada e integradora, destacando implicações na concepção e gestão de processos curriculares, recorremos a um fato histórico para melhor posicionar a atualidade desse debate. O fato em questão é o Seminário "CIEP Critica e Autocritica", realizado nos dias 8 e 9 de junho de 1991, em Niterói, no Rio de Janeiro. Com o propósito de discutir a realidade dos Centros Integrados de Educação Pública (CIEPS), o evento culminou com um encontro histórico com as presenças, conjunta, de Paulo Freire e Darcy Ribeiro após o retorno do exílio político de ambos, resultado do golpe militar de 1964. Fato que, por si só, permitiu aos participantes do Evento o inusitado de um encontro de dois grandes intelectuais brasileiros, defensores ferrenhos da escola pública, unitária e para todos.

Segundo Faria e Silva (2008), para melhor posicionar a grandiosidade de ambos, guardadas as singularidades da vida pública de cada um, Freire e Ribeiro visavam a construção de uma escola pública para todos em consonância com a Constituição Federal de 1988.

Com percursos que ora se entrecruzam e ora se afastam, as temáticas de estudos sobre a educação e o povo brasileiro são o mote para o conjunto de obras escritas por ambos, bem como a atuação na esfera pública no desempenho de funções governamentais. Além de, 
obviamente, a defesa incontestável pelo retorno à vida pública no Brasil, silenciada por quase duas décadas de exílio, em ambos os casos (FARIA, 1997).

Nesse contexto, o presente ensaio pretende resgatar os fragmentos das falas de Freire e Ribeiro no Seminário de 1991, referenciando, especialmente, a importância das experiências de educação em tempo integral que foram forjadas pelos CIEPs, no Rio de Janeiro; posicionar no cenário atual o debate sobre a escola em tempo integral e a educação integral e integrada; buscar localizar, na discussão curricular, aspectos de construção de propostas formativas que, em alguma medida, consubstanciam elementos que remetem às preocupações de Freire e Ribeiro, em especial às questões referentes a importância do tempo e do espaço em educação ${ }^{3}$.

O contexto atual para tal problematização poderia ser encaminhado via um conjunto bastante consistente de legislações, entre elas, como destaques, o Estatuto da Criança e do Adolescentes (BRASIL, 1990) e a Lei de Diretrizes e Bases da Educação Nacional (BRASIL, 1996). Contudo, o fazemos a partir do Plano Nacional da Educação - PNE (2014-2024), referenciando especialmente a Meta 6, que pode, desde o nosso entendimento, ser apresentada como uma síntese ao propor diretrizes para a educação em tempo integral, escolas em tempo integral e educação integrada e integradora. Com o PNE e a partir dele vemos um certo movimento de alguns estados e municípios brasileiros no sentido de buscar criar estratégias para a ampliação do tempo de permanência de crianças e adolescentes que frequentam o ensino fundamental e médio, em práticas educativas realizadas no interior de escolas públicas e/ou em parcerias com Organizações Não Governamentais e de Terceiro Setor. Um exemplo nesse sentido é a rede estadual de ensino de Tocantins onde, desde 2011, cresce o número de municípios que oferecem escolas estaduais de tempo integral, muito embora não se constitua numa modalidade de ensino ofertada ao universo de alunos e alunas. A realidade de Tocantins pode ser visualizada em vários dos estados brasileiros, onde prevalece mais a concepção de um aluno de tempo integral do que uma escola de tempo integral.

\section{Diálogos entre Paulo Freire e Darcy Ribeiro}

A primeira parte desse ensaio tem como referência fragmentos das transcrições das falas de Freire e Ribeiro no diálogo realizado no encerramento do Seminário CIEP - Crítica e Auto-Crítica, sessão datada de 9 de junho de 1991, extraídos do documento intitulado "O

\footnotetext{
${ }^{3}$ Esse ensaio marca uma escrita ainda inicial resultado da aproximação com os campos empíricos que compõem a investigação 'Educação Integral entre práticas de educação escolar e não escolar. Perspectivas de formação humana e desenvolvimento social (2018-2021)', do grupo de estudos do CNPq Estudos e Práticas em Educação Não Escolar ao qual os autores fazem parte.
} 
encontro das águas: diálogos entre Paulo Freire e Darcy Ribeiro", de autoria de Lia Faria e Rosemaria J. Vieira Silva, escrito em 2008. Ambas as manifestações referenciam a importância das experiências de escolas de tempo integral desde a Escola Parque de Teixeira até os CIEPs de Darcy Ribeiro.

Damos destaque a elas, primeiramente através da exposição de Freire e, na sequência, com o pronunciamento de Ribeiro ${ }^{4}$.

\section{Trechos da exposição de Paulo Freire}

O sujeito da educação em Paulo Freire é concebido em um amplo quadro de referências sobre as dimensões ontológicas, sociais, políticas e culturais que formam o processo de humanização de modo que, envolvido permanentemente nesse processo, esse sujeito constrói a si mesmo a partir de relações subjetivas e intersubjetivas em meio às contradições do mundo humano (FREIRE, 2005). Em "Educação como Prática de Liberdade", Freire apontava que um processo educativo que objetive atender ao pressuposto da humanização deveria propor ao sujeito "[...] a reflexão sobre si mesmo, sobre seu tempo, sobre suas responsabilidades [...]" (FREIRE, 1967, p. 57), diante do que, em "Pedagogia do Oprimido", problematizou como mecanismos de desumanização, como a "[...] injustiça, exploração, opressão, violência [...]”, etc. (FREIRE, 2005). Depreende-se dessa concepção um sentido integral de educação que visa, dinamicamente, instituir espaços de autoformarão e de práticas colaborativas que resultem na construção de atributos intelectuais, éticos e políticos de engajamento do sujeito em um mundo de complexas relações e transformações. Nos trechos destacados da fala de Freire a seguir é possível localizar preocupações que evidenciam o seu engajamento na proposição de uma escola que incorpore esse sentido em seu modo de se situar socialmente, em suas práticas didáticas e curriculares. Para Freire, o CIEP parece se inserir nesse marco.

[...] minhas amigas e meus amigos, as palavras primeiras que eu gostaria de dizer aqui, agora, são palavras de agradecimento. Talvez, eu até devesse dizer que, perdendo um pouco a humildade por minha conta e por Darcy, a gente não é vaidoso excessivamente, mas a gente tem a dose necessária. Mas, perdendo um pouco a humildade, eu diria a vocês que homens como Darcy, a quem eu me junto, não encerram coisa nenhuma, inclusive encontros como esse. [...] Eu sou amigo do Darcy, nós somos da mesma idade, possivelmente eu sou mais velho um ano que Darcy, mas eu comecei

${ }^{4} \mathrm{O}$ uso de parênteses para fazer a supressão de fragmentos de falas incorpora, além das eliminações presentes original, ver Faria e Silva (2008), outras que julgamos necessárias não pelo seu teor, mas para reduzir o tamanho do texto. 
o meu querer bem a Darcy por uma admiração ao intelectual Darcy, quando ambos éramos, faz tempo, muito jovens. [...] quando eu estive com Darcy pela primeira vez, eu tinha tido essa experiência anterior e como éramos, $e$ somos da mesma geração, a minha nervosidade anterior, e como éramos e somos da mesma geração, a minha nervosidade foi menor. Mas eu me lembro ainda hoje da emoção com que eu estive diante da cara moça, quase menina, da sua inquietação. E daí em diante ficamos, mesmo que não com encontros assíduos, mas ficamos sempre sabendo um da existência do outro. [...] essas estórias, esses pedaços de estórias, no fundo, fazem parte da nossa história, da nossa história de educadores, de intelectuais deste país, por isso mesmo de políticos deste país, um pedaço da história maior que é a história nossa de nós todos no Brasil. [...] é o meu agradecimento a vocês de ter me trazido aqui. Porque desde que eu cheguei do exílio esta é a primeira vez que estamos juntos em público, sobretudo não fazer, eu espero, não negaria, mas espero nunca fazer uma exposição acadêmica, com ares de rigorosa, sobre educação, sobre isso, sobre aquilo, mas um encontro em que também não fechando nada, mas sobretudo abrindo mais, a gente diz da gente, a gente diz da luta da gente, a gente diz da capacidade e da necessidade de querer bem, de amar e do compromisso da gente com a escola pública, com a educação séria, com o povo brasileiro. E quando eu digo povo brasileiro todo mundo tá sabendo que eu não tô falando num certo tipo de gente [...]. Eu digo povo brasileiro e estou repetindo aqui o que me disse um dia a uma operária em São Paulo. Ela disse: 'Quando eu falo em povo, eu estou falando de quem não pergunta quem é povo'. E é isso mesmo, o povão sabe quem é o povo, não pergunta quem é povo. [...] Eu quero dizer a vocês que nós todos devemos, a este homem inquieto que é Darcy, um cem números de coisas, de ideias, de propostas, de lealdades, de seriedade, de compromisso, de testemunho a nosso país, a nosso povo. Nós todos devemos isso, muito, a Darcy. Eu diria inclusive que bastava o teu arrojo nos CIEPs pra te marcar, definitivamente, na história da cultura desse país. Eu quero, então, trazer para ti não só o meu querer bem, porque tu sabes que há muito tempo eu já te dei, mas trazer pra ti a minha solidariedade de educador, de cara que pensa um pouco também a educação desse país. E a vocês todos e vocês todas o grande abraço primeiro de um cara que também briga por uma escola melhor, por uma escola mais séria, mais competente, mas, sobretudo, por causa de tudo isso, uma escola que provoque alegria nos meninos [...].

[Sobre a questão curricular, o educador/a e a concepção do tempo escolar]

Nesse trecho, Paulo Freire explicita a compreensão de que o desenvolvimento curricular se efetua em um conjunto amplo de processos dinâmicos que se irradiam em diferentes tempos e espaços da escola, conectando saberes e experiências que superem maniqueísmos sobre ensinar, aprender e produzir conhecimento. Da dinamização dos tempos e espaços da escola, inclusive da relação entre os cotidianos escolares e outros cotidianos sociais, emergem conteúdos formativos importantes para a formação integral do sujeito.

Currículo é mais do que uma grande temática, se currículo pra gente significa afinal de contas a cotidianidade da escola e a cotidianidade pensada também da escola, se currículo pra gente significa o conjunto de relações que se dão na intimidade da escola, e da escola com seu mundo

RIAEE - Revista Ibero-Americana de Estudos em Educação, Araraquara, v. 15, n. 2, p. 560-577, abr./jun. 2020. e-ISSN: 1982-5587. 
mais próximo, portanto, se currículo significa desde o estabelecimento de limites e de horários para atividade docente e significa também uma compreensão crítica do ato de ensinar e do ato de aprender, não é possível deixar de se preocupar, na inteligência do currículo, com o tempo da escola. [...] o tempo dos educadores, dentro da escola, tem que ver exatamente com a produção do saber, com a produção do conhecimento. Do tempo que a criança precisa para participar da produção do saber, e não para receber pacote de saber. É fundamental. E eu acho que um educador progressista que não pensa no tempo e que não se preocupa com o tempo permeando toda vida curricular da escola, ele está com o endereço também errado. E eu não tenho dúvida, Darcy, de te dizer que tu és um dos educadores desse país que melhor viram, pela tua própria experiência junto a Anísio, que melhor viram a questão do tempo.

[Sobre as crianças brasileiras e o direito à educação]

Nesse excerto, Paulo Freire sublinha um aspecto fundamental da concepção de Educação Integral nos CIEPs: o específico da escola não está na transmissão de um saber imóvel no tempo, delineado em torno de disciplinas curriculares, mas na produção de novos saberes decorrentes de uma visão dinâmica da história. Igualmente, vincular à escola serviços ou experiências que assistam o sujeito no hall das necessidades requeridas para que as condições físicas, psicossociais e culturais envolvidas na produção do conhecimento sejam contempladas. Por isso, ele não se opõe ao fato de que, na escola, também se instalem ações intersetoriais entre assistência social e saúde, por exemplo, uma vez que as restrições impostas por mecanismos sociais de pauperização da população brasileira fazem da escola uma instituição decisiva na promoção da cidadania através de políticas públicas intersetorializadas. $\mathrm{O}$ direito à educação, nesse sentido, é condição e, ao mesmo tempo, consequência dessas políticas.

Não é possível continuar, de um lado, a negar que as crianças brasileiras e obviamente as crianças das classes populares entrem na escola. Porque o que há é uma proibição mesmo, são proibidas de entrar, só faltam escrever $o$ ato proibitivo. [...] é um absurdo, crianças que se evadem, a evasão escolar é um cinismo. Os meninos são expulsos, porque não podem ficar lá dentro, pela forma como o tempo, o tempo de trabalhar, o tempo de produzir, o tempo de ser e de re-ser é um tempo que lhes é negado. Sobre os CIEPs, não é só pro menino também do povo não, é pro outro também chamado menino, gueto não. Porque nós não queremos fazer desse país um gueto. Mas o CIEP ao mesmo tempo em que ele propõe a compreensão e o uso diferente do tempo, nesta proposta ele reeduca, ele forma diferentemente a própria educadora. É isso que certos intelectuais metidos a progressistas não entendem. E inclusive nisso é muito dialético, quer dizer, o CIEP está convencido de que a teoria passa pela prática e vice-versa; não é possível dicotomizá-las. [...] A tua genialidade está em que a grande maioria não vê e tu vês. E os outros ficam dizendo: esse cara é doido. Não é doido, é sincronizado com a história. Eu até diria, eu tenho uns nomes bons 
pra esse tipo de gente, acho que em primeiro lugar o mundo precisa desse tipo de gente, é o que eu chamo de "sanidade insana". O mundo não vai pra frente com gente sadia somente, não dá, gente bem comportada, seriazinha demais [...] $O$ mundo só acerta assim, com essa insanidade sã, com essa sã insanidade, essa contradição da gente mesmo que faz o mundo. Um pouco poético também. [...] gente poderia até, se esse fosse tempo pra isso, o espaço, a gente poderia fazer uma listagem das positividades da proposta dos CIEPs e sair sublinhando item por item, a importância histórico-social e pedagógica e política desta proposta. Mas eu quis tomar apenas essa do tempo, mas eu não quero terminar sem tomar uma outra, cujo discurso sempre me irrita, que é a seguinte: a crítica que se faz aos CIEPs dizendo-se que a escola, a especificidade, essa é a palavrinha que inventam, a especificidade da escola é ensinar, por isso mesmo a escola não é nem hospital, nem é albergue, nem é restaurante. Nosso país tem lamentavelmente, não porque a gente queria, uma necessidade enorme de comida pra aqueles que não comem, e aí a escola também faz uma merenda melhor, e isso e aquilo. Mas o que eu quero dizer é o seguinte, a especificidade da escola, que é a produção do conhecimento, eu até diria mais tecnicamente, que é o espaço e o tempo em que se deve conhecer o conhecimento que já existe, em que se deve trabalhar para experimentar a possibilidade de criar o conhecimento que ainda não existe. Isso afinal é a educação. Você vê que é uma mentalidade, isso é uma concepção imobilista da história. Essa gente não quer mudar nada. Portanto se nega na intimidade da escola o conflito social, é atrasado isso, profundamente atrasado.

\section{Trechos da exposição de Darcy Ribeiro}

Aqui Ribeiro se mostra um homem, antes de tudo, modesto quanto a sua condição de intelectual e de educador. Ao evidenciar os feitos de Paulo Freire e de Anísio Teixeira como exemplos de sabedoria e de comprometimento com a educação do povo brasileiro, não somente referência a necessidade de aumentar o tempo de permanência de crianças e adolescente nas escolas, mas, sobretudo, de enfrentar gravíssimos pontos de estrangulamento na educação escolar que se traduziam, principalmente, em repetências e evasões. "Como Anísio sabia que era impossível melhorar todo o sistema de uma vez, fez um experimento que foi para nossa geração comovedor, que era a Escola Parque da Bahia” (RIBEIRO). Outro fator a destacar, tanto na perspectiva de Freire, Anísio e do próprio Ribeiro, é o esforço realizado no sentido de que as escolas pudessem entrar na cultura das cidades. Não se tratava de nada novo, em verdade, estava Ribeiro a recupera a ideia de Teixeira e Freire que foram a fonte de inspiração da filosofia educativa implantada nos CIEPs, também por isso alvo de tantas críticas que emergiram, inclusive, da categoria dos professores.

O que é Paulo na educação não preciso dizer, vocês sabem mais do que eu. Eu vi Paulo se exercer, Paulo é a consciência e a emoção da educação brasileira, [...] Paulo é a sabedoria da educação brasileira, mas eu acho 
que o traço fundamental é esse, é de um respeito de educador pelo educando. [...] Paulo, esse pessoal que está aqui é a prova testemunhal, carnal, nessas belas pessoas que estão aqui, de que as ideias se encarnam nas pessoas. E, quando se encarnam, elas ganham a possibilidade de existirem, de se perpetuarem. A ideia do Anísio, que é de todos educadores, do Brasil ter aquela escola que todo mundo tem [...] a única coisa profissionalizante realmente é aprender a ler e escrever e contar. Lula, porque sabia ler, escrever e contar, entrou na fábrica e virou metalúrgico, quase foi Presidente da República ${ }^{5}$. Se fosse analfabeto, teria ficado varrendo a fábrica, varrendo a porta da fábrica. [...] Anísio sabia que era impossível tomar o sistema todo e melhorá-lo de uma vez, o Anísio fez um experimento, que foi pra nossa geração uma coisa comovedora, que é a Escola Parque da Bahia, no bairro mais miserável da Bahia, era um bairro de palafitas, na lama, na merda. Naquele bairro, o Anísio fez a Escola Parque da Bahia. [...] e a escola era para quê? Pra receber as crianças quatro horas antes ou quatro horas depois da escola classe. E ele tentou melhorar as escolas classes, os meninos tinham suas aulas na escola classe, e iam pra Escola Parque. [...] $O$ nosso povo encontra uma imensa dificuldade de se impor [...] na cidade tem de entrar na cultura da cidade, cultura letrada. E essa cultura só tem uma porta, é a escola. [...] pois bem, esse povo está na cidade e tem que ter o que tem as crianças do mundo inteiro: uma escola que tem que ser de tempo total. A melhor casa da minha cidade, onde eu nasci, minha mãe era professora, era a escola. As escolas do Rio de Janeiro, basta olhar o que tem em Botafogo, na Tijuca, em Copacabana, ou as escolas que o Anísio fez aqui, Escola Guatemala, Escola Estados Unidos, Escola Argentina, cada uma delas custa mais caro que um CIEP. [...] Como é que se pode organizar a educação, com escolas que não funcionam?

[Sobre a alfabetização e a precarização do trabalho do professor]

Atento às questões de seu tempo, Ribeiro não somente criticava o analfabetismo da população, mas, especialmente, o tipo de educação bancária ofertada pelas escolas. Apresentava a baixa oferta de horas de estudo comparativamente ao Japão, Estados Unidos e França, a precariedade de instalações e de materiais, o professor mal remunerado, a baixa dotação orçamentária como limitantes para o aprendizado da população escolar (CHAGAS, 2016, p. 112).

Se você define alfabetização como o Paulo define, como defino eu, alfabetizando é quem é capaz de escrever um bilhetinho e ler um anúncio de jornal. Se você define como tal, 60\% das crianças de São Paulo são analfabetos. Nós estamos produzindo agora os analfabetos do futuro, o que é incrivel. [...] a professora ganha hoje uma sexta parte do salário que recebia. Havia uma profissão que era marido de professora: casar com professora era um grande negócio. Minha mãe viúva podia criar dois filhos dela, eu e теu irmão, e os irmãos dela, porque o pai morreu cedo. Quer dizer, uma professora podia manter, como o médico também.

${ }^{5} \mathrm{O}$ ex-presidente Luís Inácio Lula da Silva foi presidente do Brasil em duas gestões que corresponderam aos anos de 2003 a 2011. 


\section{A ampliação do tempo e do espaço em educação: os CIEPs, o Programa Mais Educação e o Plano Nacional de Educação (2014-2024)}

A partir do diálogo de dois grandes expoentes da história da educação brasileira, resgatamos a importância histórica que assumiu a dimensão do tempo nas experiências de educação nas escolas CIEPs do Rio de Janeiro, tal qual evidenciado no diálogo descrito. Mesmo que sendo uma segunda geração de escolas de tempo integral, os CIEPs foram planejados dando sequência à Escola Parque de Anísio Teixeira, em Salvador, inaugurada nos anos de 1940.

Com uma abrangência maior, em 1980, os CIEPs são apresentados como uma modalidade de escola que passa a compor o emergente cenário do desenvolvimentismo neoliberal no Brasil, contudo, vindo pelas mãos de políticos do trabalhismo histórico, que lhes atribuiu características especificas (CHAGAS, 2016).

Posteriormente, nos dois primeiros anos de 1990, experiências similares foram desenvolvidas em outras regiões do país, entre elas, os Centros Integrados de Atendimento à Crianças - CIACS, implementados no governo de Collor de Melo (1990-1992). Contudo, é inegável que foram os CIEPs as escolas de tempo integral que melhor representaram o ideário de uma política de educação voltada para os filhos de trabalhadores, cuja proposta pedagógica centrou-se em sete eixos: vontade política, linguagem e alfabetização, integração educação/cultura, democratização das relações dentro da escola, avaliação, essencialização de conteúdos/interdisciplinaridade e formação permanente de professores (CHAGAS, 2016).

Mais recentemente, sustentado na necessidade de enfrentar os baixos indicadores de qualidade da educação brasileira, especialmente, em relação aos ditames de organismos internacionais, foi visto organizar-se e consolidar-se, no país, o Programa Mais Educação PME. De largo alcance, com abrangência nacional, vigorou de forma mais intensa no Brasil entre os anos de 2008 a 2016 . O PME retoma o ideário da educação em tempo integral agora forjado pelo viés da insurgência do terceiro setor no campo da educação, a exemplo da Fundação Banco Itaú, que mesmo antes do ano de 2008 já propunha, por meio de financiamento, projetos sociais de bases didático-pedagógicas para consolidar o que seria depois o Mais Educação.

${ }^{6}$ O Programa Novo Mais Educação foi criado pela Portaria MEC n ${ }^{\circ}$ 1.144/2016 e regido pela Resolução FNDE $n^{\circ} 17 / 2017$, se constituindo numa estratégia do Ministério da Educação para melhorar a aprendizagem em língua portuguesa e matemática no ensino fundamental, por meio da ampliação da jornada escolar de crianças e adolescentes, otimizando o tempo de permanência dos estudantes na escola. Disponível em: http://portal.mec.gov.br/programa-mais-educacao. Acesso em: 12 de nov. de 2018. 
O PME proporcionou a ampliação de tempo, espaços e oportunidades educacionais baseando-se no pressuposto da formação integral. Esta se expressa pela conexão das aprendizagens da sala de aula, vivências em oficinas de áreas diversas, organizadas por eixos temáticos, saberes comunitários que adentram a escola por meio de diferentes parcerias, oferta de alimentação entre os turnos, acrescendo para sete horas diárias a carga horária mínima de permanência na escola/ong/comunidade, em consonância com as legislações. Merecem destaque os Planos Nacionais de Educação (2001-2011 e 2014-2024), que vem marcando o lugar da ampliação da jornada escolar na educação pública brasileira e, muito especialmente, a versão 2014-2024 quando propõe a Meta 6, subdivida em 9 estratégias de ação ao reafirmar, seguindo as orientações presentes na Constituição Federal de 1988 e na Lei de Diretrizes e Bases da Educação Nacional de 1993, a escola de tempo integral como uma possibilidade a ser concretizada no Brasil. O objetivo não é somente o da ampliação dos tempos de permanência na escola, mas a relação dessa ampliação com a qualidade do ensino e das aprendizagens.

Os CIEPs, CIACs e o PME, cada um em seu tempo sócio histórico, marcadores políticos, objetivos e abrangência geográfica e populacional possuem pontos em comum, em especial, no que se refere à ampliação do tempo que crianças e adolescentes de classes populares, socialmente vulnerabilizadas, permanecem na escola e em práticas socioeducativas por mais 4 horas diárias. Essas últimas atividades, podendo ser realizadas em outros espaços sociais, no âmbito das comunidades e/ou a partir de parcerias com serviços que realizam projetos sociais, muitos deles com reconhecidas características educativas, outros marcados por vieses mais assistenciais, por vezes, assistencialistas.

No caso do PME, para além da abrangência no âmbito do território nacional, o Programa propõe, mesmo que com dificuldades de diversas naturezas, dialogar com a cultura das comunidades. Constitui-se numa oportunidade de levar para dentro das escolas a diversidade cultural, em suas mais diversas manifestações, existente no entorno da instituição escolar. Desta forma amplia-se as concepções do que seja o espaço educativo, o que seja educar para além de práticas realizadas pelo sistema de educação, em especial, no âmbito do ensino fundamental, mesmo que, atualmente, fragilizadas com a proposta do Novo Mais Educação (Portaria MEC no 1.144/2016). Contudo, é impossível negar que o PME reverbera de diferentes modos no cenário nacional. Tem sido o mote para a criação de alternativas ao modelo hegemônico. Algumas escolas públicas municipais e estaduais que tiveram acesso aos recursos materiais e financeiros pelo Programa, que chegava na modalidade dinheiro direto na escolar, ainda mantém a ampliação do tempo, agora com os professores concursados ou 
contratadas atuando, não mais tendo os monitores do PME como educadores responsáveis pelas oficinas pedagógicas. Outra questão é a verificada em alguns estados e municípios que estão propondo políticas de ampliação de jornada em algumas escolas de suas redes, considerando principalmente a dimensão compensatória da escolar em tempo integral.

Em meio à pluralização das experiências decorrentes dessas políticas, faz-se necessário localizar a especificidade de conceitos que, comumente, podem ser associados de modo redundante ou equivocado para referir-se a elas: escola de tempo integral, educação integral e educação integrada/integradora.

Segundo Moll (2012), a dimensão do tempo integral na escola possui dois sentidos: um referente à organização e ampliação do tempo que os estudantes permanecem na escola além da jornada de um turno e, outro, remete a um conjunto de necessidades formativas de diversos campos, entre eles, o cognitivo, estético, ético, lúdico, espiritual, físico-motor, entre outros. Em ambas as perspectivas a escola se apresenta como dispositivo educativo que age sobre o indivíduo com vistas ao anseio geral da sociedade enquanto ação, aprimoramento e evolução.

Possuindo um sentido mais amplo, a educação integral pode ser compreendida enquanto um agir em educação, envolvendo diversas e abrangentes dimensões da formação de indivíduos (CAVALIERE, 2010). Faz referência à vida da pessoa e da comunidade em que se insere porque deve prever e capacitar de acordo com as potencialidades de cada uma e cumprir-se ao longo da vida humana, resultando num modo de ser e estar daqueles que partilham de um modo humanitário de viver.

Já sob viés de uma educação integrada/integradora se associam práticas assistenciais às escolas na garantia do acesso e permanência de sujeitos situados social e economicamente em condições de desvantagem. Diante dos problemas que afetam a escola pública brasileira e em face das suas possibilidades de evolução a curto/médio prazo, pode considerar-se que há que lançar mãos a expedientes que contribuam para diminuir a desigualdade social e educativa que minam a coesão da sociedade brasileira e que pode passar, por exemplo, por experiências de práticas de educação integrada ou integradora.

\section{O tempo e o espaço no currículo: dimensões fundantes da educação integral (integrada e integradora)}

As experiências dos CIEPs e do PME remetem a possibilidades de construção de cotidianos escolares em que se valorize a relação com os saberes como processo de natureza 
criadora e criativa, dinamizado pela pluralidade de enfoques que busquem superar o estigma da aprendizagem como aquisição de proficiência no domínio de tipos específicos de conhecimento acadêmico. Como aponta Sacristán: “[...] os significados dos objetivos educacionais não podem estar circunscritos aos conteúdos dos limites estabelecidos pelas tradições acumuladas nas disciplinas escolares” (2013, p.23). Emergem dessas experiências um sentido de currículo que reside, fundamentalmente, na compreensão de que o espaço e tempo na escola são dimensões plásticas e moldáveis imbricadas na produção de oportunidades formativas estruturadas por objetivos mais amplos de socialização humana. Esses objetivos não descartam os conteúdos acadêmicos que informam as agendas políticas de escolarização, mas os situam em uma rede de intencionalidades para o desenvolvimento do sujeito como ator de práticas sociais e culturais constituídas em múltiplos arranjos de saberes e modos de ação que devem ter lugar em uma escola que se pretenda integral, integrada e integradora. A formação desse sujeito se vincula a um espectro diverso de formas de mediação que necessitam provocar processos de aprendizagem socialmente referenciados, os quais lhe possibilitem a compreensão de si como ator de relações, a inteligibilidade dos elementos objetivos e subjetivos que constituem os contextos da vida e o engajamento ativo necessário à sua transformação, visando um projeto de justiça social, como salientou Freire.

A presença de práticas comumente classificadas como "não formais" no espaço escolar, como as do PME e de iniciativas de educação integral, induziram encontros interessantes entre diferentes paradigmas formativos em um mesmo território, deslocando fronteiras e produzindo arranjos na escola que questionam, inclusive, a adjetivação "não formal" ou "não escolar" a certos tipos de saberes e vivências outrora típicos de processos educativos desenvolvidos fora das instituições escolares (SEVERO, 2018). A dilatação das dimensões temporais e espaciais da educação está se dando, nesse sentido, em experiências que "desterritorializam" os saberes e vivências dos seus lócus habituais e que, por isso, promovem uma circulação mais dinâmica de elementos que tangenciam diferentes aspectos do desenvolvimento das pessoas e dos grupos humanos.

Entende-se que a escola, na perspectiva da Educação Integral, deve ser um lugar de encontro onde sujeitos e culturas se "reterritorializem" através de currículos e pedagogias enraizados em uma noção de cidade educadora, ou seja, de que a rua e o bairro, por exemplo, são lócus produtores de experiências que podem ser reelaboradas no interior da escola. Desse modo, ao propor a ampliação do tempo escolar, as políticas curriculares de Educação Integral devem considerar que a saída do sujeito da "rua" para permanecer na escola por um período 
estendido não implica em deixar a "rua" fora da escola ou separar o sujeito dos seus espaços de inserção comunitária (ZANARDI, 2016).

Paulo Freire convidava o público presente no Seminário CIEP - Crítica e Autocrítica a conceber o currículo como conjunto de relações com o saber que se tecem em processos de apropriação, criação e comunicação, correspondendo a uma visão emancipatória de formação humana. Em Paulo Freire, o currículo para uma educação integral é pensado como um elemento que se estrutura em cotidianos de produção de sentido na e pela escola, nos quais diferentes fontes de saber dialogam entre si e ampliam as possibilidades do conhecimento provocar processos de crítica e transformação social. Como se pode depreender, o tempo curricular consistiria em uma chave essencial na compreensão do percurso que professores(as) e estudantes trilham para se apropriar e produzir o saber sobre si mesmos e sobre o mundo em que vivem, nas suas macro e micro esferas. Não se resume ao tempo de permanência na escola, mas envolve o estar e o fazer presença em uma pedagogia dialógica interessada em mobilizar autorias criativas, vontade política e aptidões de pensamento e ação que se vinculam a conhecimentos de diferentes origens disciplinares e que convergem para zonas de intersecção e recriação. O tempo curricular precisa ser dimensionado considerando o tempo que o professor demanda para produzir o saber que ensina em uma dimensão gnosiológica e didática (se apropriar do conhecimento do campo ao qual se dedica, transpô-los didaticamente e criar conexões com outros conhecimentos e fontes de contexto) e que o estudante também se apropria e recria o conhecimento mediante esquemas de significação e vinculação com o real vivido. O tempo curricular consiste no tempo do conhecer como processo de curiosidade epistemológica que move o pensamento, de diálogo com o histórico e o cultural contido na experiência individual e coletiva das pessoas, de questionamento, de sensibilização e de trocas interpessoais, tendo em vista a construção de comunidades engajadas no bem comum. No livro "A Educação na Cidade”, Freire disse ser

[...] impossível pensar a prática educativa, portanto a escola, sem pensar a questão do tempo, de como usar o tempo para aquisição de conhecimento, não apenas na relação educador-educando, mas na experiência inteira, diária, da criança na escola. A escola progressista, séria, não pode estragar o tempo, botar a perder o tempo de a criança conhecer. (FREIRE, 2005, p. 46).

Há uma clara implicação entre esse modo de conceber o tempo curricular e o que se compreende como espaço pedagógico. A implicação está contida na pergunta: “onde a escola opera o projeto formativo a que se propõe e investe tempo"? Uma resposta rápida seria a sala de aula. Inegavelmente, a sala de aula é um potente e indispensável espaço de produção de 
relações com o saber, mas a extensão da proposta de formação humana engajada na perspectiva de Educação Integral não se encerra nesse local regulado, muitas vezes, pelo tempo da exposição oral ou pela "fixação" de conteúdos através de atividades dirigidas. O espaço pedagógico na Educação Integral pode ser demarcado em diferentes ambientes, escolares e extraescolares, que possam servir de lócus para o encontro formativo entre pessoas e contextos, e isso inclui a comunidade em que a escola está inserida e o ciberespaço. Importa dizer que a construção do espaço pedagógico não está posta como um dado prévio para o currículo, encerrando-o em um local determinado, comumente uma sala de aula, mas acontece na medida em que as mediações para o desenvolvimento curricular convertem em territórios educativos, cenários que carreguem potenciais para serem explorados didaticamente e proporcionem encontros, convivências e aprendizagens, de acordo com as intencionalidades que norteiam a ação docente.

Se o espaço pedagógico da escola não se define unicamente pela sala de aula, também não o é em razão do tipo de informação que se veicula em uma atividade educativa, entendimento que poderia restringir um espaço como sendo pedagógico quando apenas estivesse sendo usado por um(a) professor(a) para ensinar conteúdos disciplinares presentes nos currículos prescritos. O espaço pedagógico, como um espaço de relações sociais, se delineia em torno de oportunidades de aquisição, criação e socialização de saberes diversos como manifestações que atuam na formação das pessoas e, nesse sentido, pode ser palco de diferentes arranjos que conectam professores(as)-estudantes, estudantes-estudantes, professores(as)-professores(as), sujeitos-meio, etc. Esse espaço é convidado, em Freire e Darcy Ribeiro, a não se isolar em estruturas fechadas às conexões externas, pois isso impediria a escola de "curricularizar" questões comunitárias importantes para sua contextualização como instituição atenta e engajada na construção da sociedade para além dos seus muros. Sobre esse aspecto, é interessante situar que

frente a una pedagogía que todo lo quiere escolarizar se vislumbra otra donde late, las más de las veces de forma inconsciente, un proyecto desescolarizador. La escuela sale de su territorio, no para poblar de escuela su exterior, sino para lograr fuera lo que dentro no es posible. (TRILLA, 1985, p. 47).

O autor aponta para as relações entre as diferentes pedagogias que delimitam os processos educativos em contextos escolares e não escolares, sugerindo que, ao olhar para as aprendizagens que se dão no marco de espaços exteriores à escola, a pedagogia da escolarização ou da forma escolar pode capturar elementos que auxiliem a ressignificação de 
suas razões históricas, redimensionando o sentido de escola para dar conta da integralidade do desenvolvimento humano e social, princípio esquecido ou negligenciado por muitas tendências curriculares e didáticas tradicionais.

O argumento de organização do espaço e do tempo no currículo da Educação Integral delineado ao longo do texto, embasado no diálogo entre Freire e Darcy, advoga pela superação da fragmentação do saber a partir do antagonismo entre aprendizagem escolar e não escolar. De certo, o campo das aprendizagens não escolares constitui um universo que dificilmente possa ser curricularizado, tendo em vista que se vincula a um campo de relações plurais de subjetivação e socialização impossíveis de serem sintetizadas em um projeto institucional que pretenda incorporar todas as demandas e possibilidades de formação humana. Embora dinâmicos e plásticos, o tempo e o espaço na educação escolar são recortes que retratam um ponto específico na trajetória de vida das pessoas. A perspectiva da aprendizagem ao longo da vida, como um paradigma de educação integral, lembra o desafio de sociedades que desejam criar e consolidar espaços inclusivos e impulsionadores de relações educativas em diferentes esferas da vida privada e pública, visando a integração comunitária geracional e intergeracional, inovação e conservação de patrimônio, socialização de hábitos social e ambientalmente solidários e sustentáveis, fortalecimento de identidades culturais, etc.

Esses objetivos transpassam, obviamente, o projeto escolar, se irradiando em trajetórias de vida associadas a possibilidades de formação em espaços não escolares, nas quais currículos culturais e biográficos se estruturam diversamente e interagem com os currículos das escolas. Em relação a esses outros currículos, entende-se que a sociedade inspira a construção de escolas que ousem novas formas de organização curricular, abrindo-se “[...] para outras experiências e saberes, sem abrir mão dos conhecimentos escolares, mas lançando mão deles como instrumentos para a compreensão do mundo em bases distintas das que provêm da experiência imediata [...]" (GALIAN, 2016, p. 15). Isso deve servir a fim de instrumentalizar as pessoas do conhecimento necessário para, inclusive, confrontar as contradições dessa mesma sociedade, as quais estão atreladas ao que Alheit e Dausien (2006) classificam como nova ordem educativa, um modo de significação da educação baseada em economias de conhecimento que sujeitam a vida às demandas do sistema produtivo, estimulando a competitividade social através de qualificações que parecem nunca atender às expectativas de performance operacional e emocional envolvida na formação do capital humano. 


\section{Considerações finais}

A conversa entre Freire e Darcy Ribeiro permite tecer algumas considerações conclusivas relevantes ao debate atual sobre as dimensões tempo e espaço na concepção e no desenvolvimento curricular na Educação Integral, considerando o contexto desafiador que mostra uma população cada vez mais desassistida por um Estado de caráter ultraconservador inclinado aos interesses de corporações econômicas em oposição a interesses civilizatórios e de justiça social.

Em relação à dimensão espacial, entende-se a necessidade de investimento em projetos institucionais que ampliem a oferta de mediações na escola, englobando diferentes segmentos de políticas públicas que visam assistir integralmente os sujeitos para que os fins da educação escolar possam se concretizar em um cenário marcado por mecanismos de exclusão social persistentes ligados a condicionantes de saúde, situação social, etc. Ou seja, o espaço escolar é o espaço do desenvolvimento humano e social decorrente de um projeto educativo que conceba o sujeito em suas múltiplas dimensões e necessidades, a fim de se criar uma rede intersetorial de cuidados e promoção de uma agenda diversificada de aprendizagens em seus múltiplos nexos: cognitivos, afetivos, sociais, individuais, comunitários, etc. Como Freire destacou, tal essa amplitude é um indício para problematizar o argumento de que a especificidade da escola estaria em transmitir saberes universais acumulados em disciplinas acadêmicas.

Na concepção integral, esses saberes dialogam com outras fontes epistemológicas para construírem racionalidades abertas à diversidade de saberes e modos de ação. O que se ensina e se aprende ganha valor dada sua condição de permitir a reconstrução permanente desses cotidianos na direção de uma sociedade mais inclusiva, criativa e justa.

A dimensão do tempo, a Educação Integral comporta mediações que se ocupam de aportar às pessoas as condições necessárias para o seu desenvolvimento holístico. É o tempo de encontro entre ações intersetoriais e, portanto, de abordagens pedagógicas subsidiadas por mediações de políticas sociais que encontram, na escola, oportunidade para implementarem pautas estratégicas de assistência e educação social. O tempo da aprendizagem é, também, o tempo do cuidado, da convivência e do cultivo do envolvimento comunitário.

Contudo, se a duras penas, via-se construir redes de proteção e educação num diálogo inovador e, em certa medida, ousado, fazendo-se comunicar as políticas sociais e as de educação, no ano de 2016 com a Emenda Constitucional - PEC 55/2016 e seus impactos sobre o orçamento da saúde e da educação, iniciou-se um desmonte do que poderia ser uma 
aposta para o fortalecimento de experiências de educação integrada. Na sequência, o Programa Mais Educação foi substituído pelo Novo Mais Educação, resultado de restrições orçamentárias, cujos reflexos são sentidos não somente nas práticas educativas de ampliação de tempo de permanência na escola, mas muito especialmente no conceito de educação e do que seja educar.

Nesse contexto, o tempo e o espaço no currículo enquanto dimensões fundantes da educação integral (integrada e integradora) que vem demonstradas, sobretudo, por estudos realizados a partir de experiências produzidas no interior do Programa Mais Educação, passam a influenciar de modo negativo práticas de educação não escolar. Projetos sociais de caráter educativo têm seu tempo de funcionamento reduzido, muitos vem sendo terceirizados sem nenhum ganho em ternos de qualidade e efetividade social, pesando somente a redução de custos para o poder público, outros tem se reduzido ao modelo de socialização escolar, em quase nada dialogando com a realidade da comunidade onde estão inseridos. Deste novo momento da educação brasileira, nem tão novo assim, pouco restam de experiências educativas que em tudo teriam o apoio de Freire e Ribeiro.

\section{REFERÊNCIAS}

ALHEIT, P.; DAUSIEN, B. Processo de formação e aprendizagem ao longo da vida. Educ. Pesqui, São Paulo, v. 32, n. 1, jan./apr. 2006. Disponível em: http://www.scielo.br/scielo.php?script=sci_arttext\&pid=S1517-97022006000100011 Acesso em: 28 de mar. de 2019. DOI: https://doi.org/10.1590/S1517-97022006000100011

BRASIL. Lei n. 8.069, de 13 de julho de 1990. Dispõe sobre o Estatuto da Criança e do Adolescente e dá outras providências. Diário Oficial da União, Brasília, DF, 16 jul. 1990. Disponível em: http://www.planalto.gov.br/ccivil_03/LEIS/L8069.htm. Acesso em: 17 de abril de 2019.

BRASIL. Lei n. 9.394, de 20 de dezembro de 1996. Estabelece as diretrizes e bases da educação nacional. Diário Oficial da União, Brasília, DF, 23 dez. 1996. Disponível em: http://www.planalto.gov.br/ccivil_03/LEIS/L9394.htm. Acesso em: 17 de abril de 2019.

CAVAliERI, A. M. Anísio Teixeira e a Educação Integral. Paidéia, v. 20, n. 46, p. 249-259, maio/ago. 2010. Disponível em:

http://www.scielo.br/scielo.php?script=sci_arttext\&pid=S0103-863X2010000200012. Acesso em: 17 de maio de 2019. DOI: https://doi.org/10.1590/S0103-863X2010000200012

CHAGAS, M. A. M. das. Animação cultural: a inovação dos CIEPS-RJ nos anos de 1980. Curitiba: Appris, 2016.

FARIA, L. Olhar feminino sobre ideologias dos anos 60: 'discurso fundador' de uma geração. Rio de Janeiro: Ed. Uerj, 1997. 
FARIA, L.; SILVA, R. J. V. O encontro das águas: diálogos entre Paulo Freire e Darcy Ribeiro. 2008. (Inédito).

FREIRE, P. Educação como prática da liberdade. Rio de Janeiro: Paz e Terra, 1967.

FREIRE, P. Pedagogia do Oprimido. 41. ed. Rio de Janeiro: Paz e terra, 2005.

GALIAN, C. V. A. Currículo e conhecimento escolar na perspectiva da educação integral. Cadernos Cenpec, v. 6, n.1, p. 1-22, dez. 2016. Disponível em:

http://cadernos.cenpec.org.br/cadernos/index.php/cadernos/article/view/347. Acesso em: 28 de mar. de 2019. DOI: http://dx.doi.org/10.18676/cadernoscenpec.v6i1.347

MOLL, J. Introdução. In: MOLL, J. et. al. Caminhos da educação integral no Brasil: direito a outros tempos e espaços educativos. Porto Alegre: Penso, 2012.

RIBEIRO, D. Cieps: crítica e autocrítica. Encontro dos educadores Paulo Freire e Darcy Ribeiro.

SACRISTÁN, J. G. O que significa o currículo? In: SACRISTÁN, J. G. (org.). Saberes e incertezas sobre o currículo. Porto Alegre: Penso, 2013. p. 16-34.

SEVERO, J. L. R. de L. Dimensões socializadoras do currículo na perspectiva de uma Pedagogia Social: algumas aproximações. Revista de Educação, Ciência e Cultura, v. 23, n. 3, p. 157-167, 2018. Disponível em:

https://revistas.unilasalle.edu.br/index.php/Educacao/article/view/4121. Acesso em: 38 de mar. de 2019. DOI: http://dx.doi.org/10.18316/recc.v23i3.4121

TRILLA, J. Ensayos sobre la escuela: el espacio social y material en la escuela. Barcelona: Laertes, 1985.

ZANARDI, T. A. C. Educação integral, tempo integral e Paulo Freire: os desafios da articulação conhecimento-tempo-território. Revista e-Curriculum, São Paulo, v.14, n.01, p. 82 - 107 jan./mar.2016. Disponível em:

https://revistas.pucsp.br/index.php/curriculum/article/viewFile/26354/19389 Acesso em: 28 de mar. de 2019.

\section{Como referenciar este artigo}

ZUCCHETTI, Dinora Tereza; SEVERO, José Leonardo Rolim de Lima. As dimensões tempo e espaço em práticas de educação integral: implicações curriculares a partir do diálogo entre Paulo Freire e Darcy Ribeiro. Revista Ibero-Americana de Estudos em Educação, Araraquara, v. 15, n. 2, p. 560-577, abr./jun. 2020. e-ISSN: 1982-5587. DOI: https://doi.org/10.21723/riaee.v15i2.12467

Submetido em: 18/04/2019

Aprovado em: 30/11/2019
Revisões requeridas: 20/07/2019

Publicado em: 20/02/2020 